\title{
Revealing the Atomic Structure of $\mathrm{Rh} / \square-\mathrm{Al}_{2} \mathrm{O}_{3}$ Catalysts Using Low Dose Rate Electron Microscopy
}

Cheng-Han $\mathrm{Li}^{1}$, Jason $\mathrm{Wu}^{2}$ and Joerg Jinschek ${ }^{1}$

${ }^{1}$ The Ohio State University, Columbus, Ohio, United States, ${ }^{2}$ Ford Motor Company, Dearborn, Michigan, United States

Atomic resolution scanning/transmission electron microscopy (S/TEM) is nowadays a standard method used to reveal catalysts' nanostructures [1]. However, the active nature of catalysts renders them susceptible to alterations by high-energy electron beams. Resulting radiation effects, including heating, electrostatic charging, radiolysis, displacement damage, sputtering, and hydrocarbon contamination, might introduce structural artifacts and prevent interpreting the actual structure of these complex catalyst/support systems [2]. Electron-beam-assisted (de)activation of supported nanocatalysts (metalsupport interactions and interparticle interactions) needs to be considered. Hence, it is necessary to study and, ultimately, to minimize electron beam effects in order to characterize the pristine catalyst structure in these investigations.

Supported rhodium (Rh) nanoparticles are very useful in automobile three-way catalysts (TWC) by promoting exhaust gases conversion, in particular possessing lean tolerance for $\mathrm{NO}_{\mathrm{x}}$ control in a transient air-fuel environment [3]. However, $\mathrm{Rh}$ is susceptible to deactivation on alumina $\left(\mathrm{Al}_{2} \mathrm{O}_{3}\right)$ and overcoming this challenge is crucial to maximize Rh utilization in order to lower precious metal usage in TWCs [4]. To understand the mechanism of deactivation, regeneration, and, in the end, an approach to achieve long term stability, temporal evolution of $\mathrm{Rh} / \mathrm{Al}_{2} \mathrm{O}_{3}$ nanocatalysts needs to be investigated, eventually under realistic environmental conditions. $5 \mathrm{wt} \% \mathrm{Rh} / \mathrm{Al}_{2} \mathrm{O}_{3}$ catalysts were prepared by incipient wetness impregnation and were calcined at $600^{\circ} \mathrm{C}$ followed by reduction in $\mathrm{H}_{2}$ environment at $450^{\circ} \mathrm{C}$. A high $\mathrm{Rh}$ loading was chosen for ease of study and had a similar particle size distribution to a realistic low loading $(<0.5 \mathrm{wt} \% \mathrm{Rh})$.

Here, a systematic investigation of the effect of high tension $(60 \mathrm{kV}$ and $300 \mathrm{kV})$, of electron dose and of electron dose-rate on supported Rh nanoparticles has been performed to understand electron beam sample interactions and to select optimum imaging conditions in both TEM and STEM imaging mode using an image-corrected Titan G2 60-300 and a probe-corrected Themis Z. In TEM mode at $60 \mathrm{kV}$, different dose rates were applied (see figure 1). Using an initial electron dose rate of $104 \mathrm{e}^{-} / \AA^{2} \mathrm{~s}$, a typical value in atomic resolution S/TEM studies of inorganic materials, an immediate encapsulation of $\mathrm{Rh}$ nanoparticles by the $\mathrm{Al}_{2} \mathrm{O}_{3}$ support was observed that would lead to an interpretation of a stable, but altered catalyst microstructure. We systematically decreased the dose rate in our experiments, but kept the accumulation dose constant at $10800 \mathrm{e}^{-} / \AA^{2}$. At an electron dose rate above $90 \mathrm{e}^{-} / \AA^{2}$, electron-beam-assisted $\mathrm{Rh} / \mathrm{Al}_{2} \mathrm{O}_{3}$ nanowire formation as well as $\mathrm{Rh}$ nanoparticle motion and coalescence were observed (figure 1-a). At $70 \mathrm{e}^{-} / \AA^{2}$, Rh nanoparticles are encapsulated by the $\mathrm{Al}_{2} \mathrm{O}_{3}$ support (figure 1-b). With the dose rate at $30 \mathrm{e}^{-} / \AA^{2}$, neither nanowire growth nor particle coalescence were observed, and the nanoparticle motion was drastically minimized.

As a measure for minimizing obvious beam-sample interactions, the relative moving speed (nm/s) of Rh nanoparticles with the average particle size $(1.2 \pm 0.1 \mathrm{~nm})$ was estimated with respect to electron dose 
rate, as shown in figure 2. Assuming a linear dependency, it suggests that an electron dose rate below $20 \mathrm{e}^{-}$ $/ \AA^{2}$ minimizes electron beam effects on $\mathrm{nm}$-sized $\mathrm{Rh}$ nanoparticle and enables (in-situ) studies revealing the actual dynamic catalyst structure. It is noteworthy that sub-nanometer $\mathrm{Rh}$ particles (with size $<<1 \mathrm{~nm}$ ) still exhibited an observable motion even at $30 \mathrm{e}^{-} / \AA^{2}$ dose rate. This is focus of our ongoing investigation.

This study of the structure of $\mathrm{Rh} / \mathrm{Al}_{2} \mathrm{O}_{3}$ catalysts, as an example, highlights that careful atomic scale $\mathrm{S} / \mathrm{TEM}$ characterization experiments can support the development of next-generation automobile catalysts. Potential deactivation and regeneration mechanism in $\mathrm{Rh} / \mathrm{Al}_{2} \mathrm{O}_{3}$ catalysts will be discussed, based on the observation of the temporal evolution of microstructure in Rh-based catalysts post oxidation and reduction treatments.

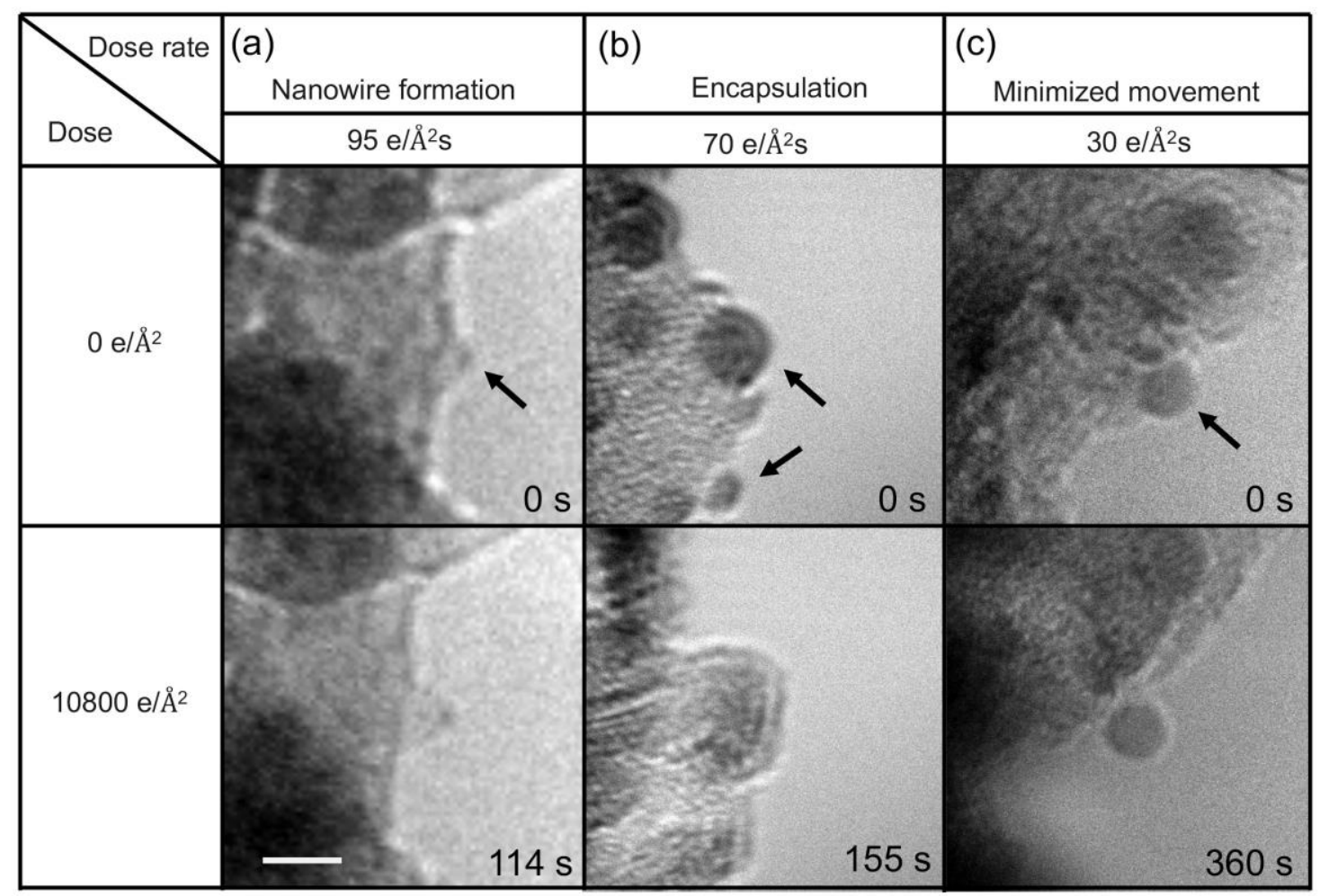

Figure 1. TEM images of $\mathrm{Rh} / \mathrm{Al} 2 \mathrm{O} 3$ catalysts taken at $60 \mathrm{kV}$ with decreasing electron dose-rate but with constant accumulated electron dose of 10800 e-/Å2. When use a dose-rate of (a) 95 e-/Å2s: Rh-Al2O3 nanowire formation is observed; (b) 70 e-/Å2s: Rh nanoparticle encapsulation by $\mathrm{Al} 2 \mathrm{O} 3$ support is observed; (c) 30 e-/Å2s: Rh nanocatalysts are stable under the beam (scale bar is $5 \mathrm{~nm}$ ). 


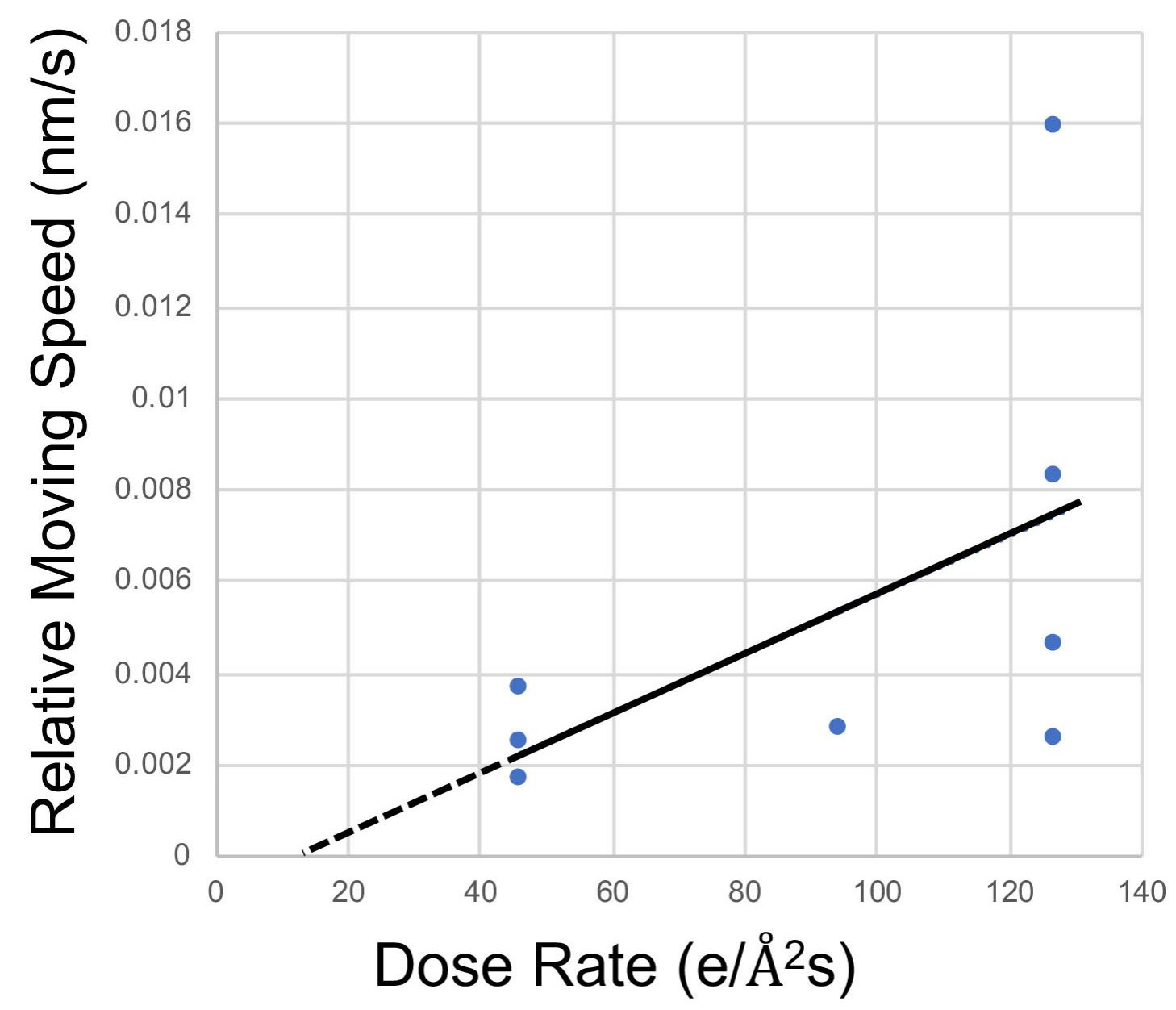

Figure 2. Measured relative speed (in $\mathrm{nm} / \mathrm{s}$ ) of $\mathrm{Rh}$ nanoparticle (with size of $1.2 \pm 0.1 \mathrm{~nm}$ as the average $\mathrm{Rh}$ particle size) motion in respect to applied electron dose-rate. A dotted line was used to extrapolate the dose-rate minimizing the movement of $\mathrm{Rh}(<20 \mathrm{e}-/ \mathrm{A} 2 \mathrm{~s})$.

\section{References}

[1] S. Helveg et al., "Atomic-scale imaging of carbon nanofibre growth," Nature, vol. 427, no. 6973, pp. 426-429, 2004.

[2] R. F. Egerton, P. Li, and M. Malac, "Radiation damage in the TEM and SEM," Micron, vol. 35, no. 6, pp. 399-409, 2004.

[3] H. S. Gandhi, G. W. Graham, and R. W. McCabe, “Automotive exhaust catalysis,” J. Catal., vol. 216, no. 1, pp. 433-442, 2003.

[4] R. Burch, P. K. Loader, and N. A. Cruise, "An investigation of the deactivation of Rh/alumina catalysts under strong oxidising conditions,” Appl. Catal. A Gen., vol. 147, no. 2, pp. 375-394, 1996. 